\title{
Consent requirements for pelvic examinations performed for training purposes
}

\author{
Elaine Gibson LLM, Jocelyn Downie SJD
}

I n September 2010, The Society of Obstetricians and Gynaecologists of Canada (SOGC) and The Association of Professors of Obstetrics and Gynaecology of Canada (APOG) issued an updated policy statement on pelvic examinations and consent. ${ }^{1}$ The updated document contains a number of meaningful improvements over the previous clinical practice guideline. ${ }^{2}$ For example, whereas the previous guideline did not require explicit patient consent, the new document states,

When a medical student is involved in patient care, patients should be told what the student's roles will be, and patients must provide consent. Patient participation in any aspect of medical education should be voluntary and non-discriminatory. ${ }^{1}$

This development is to be commended. However, the new policy statement contains a major flaw, leading to the unfortunate paradox of some women now being less protected against examinations they did not consent to. That which has been hailed by one medical resident as "a step in the right direction" ${ }^{\prime 3}$ is simultaneously a step in the wrong direction.

The performance of pelvic examinations on women under anesthesia by medical trainees is a long-established practice in Canada and elsewhere. ${ }^{2}$ It is essential that physicians be trained in the conduct of such examinations. ${ }^{2}$ There is some rationale for undertaking these examinations while patients are under anesthesia. As noted in the 2006 guideline, the pelvis of a patient under anesthesia is in a relaxed state, the trainee conducting the examination is not under time pressure, the trainee is able to relate findings with pathology found during surgery and the patient experiences reduced discomfort re sulting from the examination. ${ }^{2}$

However, in early 2010, this long-established practice became the subject of considerable controversy. Canadian news reports claimed that women under anesthesia were being subjected to pelvic examinations they did not consent to in the interests of medical training. ${ }^{4}$ The medical schools responded that patients are aware they are entering a teaching hospital and therefore know that trainees will be actively participating in their care. Further, they argued, patients sign a consent form on entry to the hospital that includes a provision indicating that students may be involved in their surgical care, including medically necessary examinations. Thus, they concluded, the patient has either explicitly or implicitly consented to the pelvic examination by a student while the patient is under anesthesia. ${ }^{5-7}$

In an article published in The Globe and Mail, André Picard, decrying a perceived reliance on "implicit" consent, referred to the practice of pelvic examinations under anesthesia as "one of those dirty little secrets of medicine." An editorial in The Globe and Mail stated that "[i]mplied consent is a useful fiction; Canadian medicine seems reluctant to part with it." ${ }^{\prime 8}$ Thus, the tenor of these articles was that medical schools that permitted examinations without explicit and specific consent were engaged in an illicit practice, and that this had to be stopped.

Evidence was produced in support of the critique. For example, reference was made ${ }^{4}$ to a study conducted in 2009 at the Calgary Pelvic Floor Disorders Clinic. ${ }^{9}$ Researchers interviewed 102 participants, most of whom had undergone gynecologic surgery in the past, about their beliefs and attitudes about pelvic examinations and consent. Only $19 \%$ were aware that a medical student might conduct a pelvic examination in the operating room. Of the participants, $72 \%$ expected to be asked for consent before the conduct of such an

\section{- KeY POINTS}

- In 2010, The Society of Obstetricians and Gynaecologists of Canada (SOGC) and The Association of Professors of Obstetrics and Gynaecology of Canada (APOG) released an updated policy statement regarding pelvic examinations performed on women under anesthesia.

- The updated statement, unlike the previous 2006 guideline that applied to "medical trainees" (explicitly including students and residents), for the most part only applies to "medical students."

- Pelvic examinations conducted for training purposes presumably constitute a battery in law, subject to the defence of consent.

- Residents need to be covered by an SOGC and APOG policy statement regarding pelvic examinations for training purposes with the same requirements that the updated statement establishes for medical students. 
examination under anesthesia. The claim of some medical schools - that women either should know by virtue of their being in a teaching hospital or that they give consent to trainee participation by virtue of forms signed on entry to hospital - may be seen to be deficient. It appears not to be generally understood by patients that students would conduct pelvic examinations while patients were under anesthesia.

In response to the public criticism of practice and the 2006 document, ${ }^{2}$ the SOGC and APOG revised their guidelines and produced the 2010 policy statement. ${ }^{1}$ As a result, medical students face a more rigorous regime than they did before. This renders their circumstance more reflective of the legal and ethical rules, which dictate that explicit consent to procedures be obtained.

However, and herein lies the problem, residents are not adequately covered by the revised policy statement. Because the 2010 statement replaced the 2006 document, the earlier guidelines are no longer in effect. A key difference between the documents is evident in the title. The 2006 guideline was entitled "Pelvic examinations by medical trainees" (explicitly including both residents and medical students); the 2010 policy statement is entitled "Pelvic examinations by medical students" (implicitly not including residents). The 2006 document consistently referred to "medical trainees," and the requirements applied to both residents and medical students. The 2010 document consistently refers to "medical students," and there is only one requirement explicitly addressing "residents" (in relation to introducing themselves to the patient before surgery).

The change from "medical trainees" to "medical students" is very important. Just as with medical students, residents will sometimes perform pelvic examinations for training rather than, or in addition to, therapeutic purposes. Some residents will have progressed to a point in their training at which they are performing pelvic examinations solely for therapeutic purposes. Others, however, are either at an early stage of learning to perform an examination or are gaining further, more sophisticated, training through performing the examination in more complex circumstances. The fact of residents performing pelvic examinations for training purposes is implicit in the inclusion of pelvic examinations in the procedural skills within core competencies required by many residency programs. Consider the following examples.

Example 1 (solely for educational purposes): an off-service resident (i.e., general surgery, family medicine, pathology) rotating through a gynecology department and performing a pelvic examination to gain experience in pelvic examinations or better understand the gynecologic process. She is not playing a role in surgical planning, so the examination is not in any way therapeutic but rather is purely a learning experience.

Example 2 (for educational and therapeutic purposes): a junior resident helping with a gynecologic surgery, but still considered an assistant. The staff person will direct the surgical approach (i.e., vaginal v. abdominal); however, the resident will examine the patient to gain an understanding of when each approach is best suited (matching the pelvic examination with planned surgery).

A pelvic examination performed by a resident for educational purposes as described above (whether solely or in addition to therapeutic purposes) without disclosure of the purposes and explicit consent to the examination for those purposes arguably constitutes a battery in law. In Canadian law, any nontrivial, intentional physical contact with another person that is harmful or offensive constitutes a battery. ${ }^{10}$ Clearly, the contact required to conduct a pelvic examination is intentionally effected and nontrivial in nature. But is it harmful or offensive? As Chief Justice McLachlin of the Supreme Court of Canada indicated in the leading case in this area, contact, unless it is "the sort of everyday physical contact which one must be expected to tolerate," meets the standard for "offensive" in the context of battery analysis. ${ }^{11}$ It is the violation of a person's bodily integrity that constitutes the offence or harm to the person.

The classic example of nonoffensive contact is being jostled in a crowd. The Chief Justice noted that sexual contact does not fall into this category of contact. ${ }^{12}$ Similarly, pelvic examinations clearly do not fall into this category. They are, therefore, offensive. Thus, it can be concluded that pelvic examinations for training purposes presumably constitute a battery in law.

Consent is a defence to a claim of battery, and consent may be express or implied. One need not have expressly indicated agreement, provided that a reasonable person in the shoes of the person doing the examination would infer from the behaviour of the patient that consent is present. ${ }^{13}$ For valid express consent, a patient must be advised of the nature of the contact to which she is agreeing. ${ }^{14} \mathrm{An}$ integral part of the nature of the contact is the purpose(s) of the examination. An examination being performed for a therapeutic purpose (e.g., to determine in what manner to conduct surgery) is of an entirely different nature than one performed for training purposes. If the pelvic examination is being performed for a solely therapeutic purpose, consent may be seen to have been given by the patient in her having consented to undergo the main surgical procedure and related subprocedures. However, if 
there is an educational purpose or component to the examination, consent cannot be inferred, nor included as part of the consent to required subprocedures; the patient needs to be advised that the examination has an educational purpose or component. Express consent with full disclosure of this educational purpose or component is legally required.

One might be tempted to argue that women know they will be subject to pelvic examinations for training purposes by virtue of having been told that they are being admitted to a teaching hospital, which entails trainees being involved in their care. However, there is no empirical evidence to support this claim, and what evidence there is appears to undermine it. ${ }^{9}$ Indeed, the SOGC and APOG conceded the untenability of the implied consent argument in the context of medical students by shifting to a requirement of explicit consent for students' involvement in pelvic examinations in the updated policy statement. As Dr. André Lalonde, former executive vice-president of the SOGC, stated in 2010,

What this new policy statement does is make it clear that patients must be aware of, understand, and consent to the involvement and roles of medical students in the care they are going to receive. ${ }^{15}$

We asked the SOGC and APOG to comment about the gap introduced by the change in the 2010 statement, and they declined to comment on the record.

A reasonable interpretation of the 2010 statement (in light of a comparison with the 2006 document) is that the guidelines that for the most part apply now to medical students do not apply to medical residents (otherwise, the authors of the policy statement should have continued to use the term "trainees" and continued to define that as including medical students and residents). There are therefore now two sets of requirements: those specific to medical students and those that apply to members of the gynecologic team, which includes both residents and medical students. Thus, it appears that medical students must meet both sets of requirements (i.e., those that apply to medical students and those that apply to the gynecologic team) while residents need only meet the set of requirements that applies to the gynecologic team. It is our argument that this is inappropriate.

With the replacement of the 2006 practice guideline by the 2010 policy statement, a substantial gap was created. Residents are subject to fewer requirements with respect to pelvic examinations for teaching purposes than are medical students, but there is no logical or legal justification for this. When conducting pelvic examinations for educational purposes, residents should be subject to the same requirements as set out for medical students in the 2010 policy statement. By switching from the language of "medical trainees" to "medical students" and therefore dropping residents from most of the requirements imposed by the policy statement, the statement arguably results in a lower level of protection for some women. Therefore, the updated statement must either be revised to adequately capture residents, or an additional policy statement should be drafted reflecting the same level of protection for women as was provided for in the 2006 guideline. Once that is done, we will be the first to applaud the SOGC and APOG for having taken two steps in the right direction.

\section{References}

1. Liu KE, Shapiro J, Robertson D, et al. Pelvic examinations by medical students. J Obstet Gynaecol Can 2010;32:873-5. Available: www.sogc.org/guidelines/documents/gui246PS1009E_000 .pdf (accessed 2011 Apr. 27).

2. Liu KE, Robertson D, Posner G, et al. Pelvic examinations by medical trainees. J Obstet Gynaecol Can 2006;28:320-3. Available: www.sogc.org/jogc/abstracts/full/200604_SOGCClinical PracticeGuidelines_7.pdf (accessed 2011 Apr. 28).

3. Quote from T. Johnston in: Bascaramurty D. Doctors add required consent to pelvic exam policy. Globe and Mail [Toronto] 2010 Sept. 15. Available: www.theglobeandmail.com /life/health/doctors-add-required-consent-to-pelvic-exam-policy /article1708824 (accessed 2011 Apr. 27).

4. Picard A. Time to end pelvic exams done without consent. Globe and Mail [Toronto] 2010 Jan. 28. Available: www.theglobeandmail .com/life/health/time-to-end-pelvic-exams-done-without-consent /article1447337 (accessed 2010 Apr. 27).

5. Neville A. Pelvic exams at McMaster [letter to the editor]. Globe and Mail [Toronto] 2010 Feb. 9.

6. Bocking A, Chamberlain S. Guidelines for pelvic exams [letter to the editor]. Globe and Mail [Toronto] 2010 Feb. 3.

7. Ross S. Teaching hospitals and consent [letter to the editor]. Globe and Mail [Toronto] 2010 Feb. 2.

8. When unknowing, hardly implied [editorial]. Globe and Mail [Toronto] 2010 Jan. 31

9. Wainberg $\mathrm{S}$, Wrigley $\mathrm{H}$, Fair J, et al. Teaching pelvic examinations under anaesthesia: What do women think? J Obstet Gynaecol Can 2010;32:49-53 Available: www.sogc.org/jogc/abstracts/full/201001 Education_1.pdf (accessed 2011 Apr. 27).

10. Malette v. Shulman (1990), 67 DLR (4th) 321, [1990] O.J. No. 450 at para 17.

11. Non-Marine Underwriters, Lloyd's of London v. Scalera, 2000 SCC 24, [2000] 1 SCR 551 at para 20.

12. Non-Marine Underwriters, Lloyd's of London v. Scalera, 2000 SCC 24, [2000] 1 SCR 551 at para 18.

13. Norberg v. Wynrib, [1992] 2 SCR. 226, 92 DLR (4th) 449 at para 26.

14. Reibl v. Hughes, [1980] 2 S.C.R. 880, [1980] S.C.J. No. 105 at para 10.

15. The Society of Obstetricians and Gynaecologist of Canada. The SOGC and APOG respond to demand for clearer guidelines regarding pelvic examinations by medical students [news release]. 2010 Sept. 15. Available: www.sogc.org/media/pdf/news/med PelvicExaminationsByMedicalStudentsENG100915.pdf (accessed 2011 Apr. 28)

Affiliation: From the Health Law Institute, Dalhousie University, Halifax, NS

Contributors: Elaine Gibson drafted the article. Both authors revised the article and approved the final version submitted for publication. 